\title{
OBITUARIO
}

\section{ENCARNACIÓN ROSA GUAGLIANONE}

(1932-2014)

El 12 de octubre 2014 falleció la prestigiosa botánica Encarnación Rosa Guaglianone, quien marcó un camino importante en el estudio de la familia botánica Cyperaceae, también realizó valiosos aportes en familias como Liliaceae, Phytolaccaceae y Smilacaceae.

Nació el 15 de abril de 1932, en la ciudad de 9 de Julio, Prov. de Buenos Aires, luego se trasladó a la Capital Federal donde en el Instituto Superior del Profesorado de la Capital egresó en 1959 como Profesora en Ciencias Biológicas.

En 1961 fue nombrada ayudante de clases y en 1965 Profesora de Botánica en el colegio Nacional de Buenos Aires. Mantuvo su

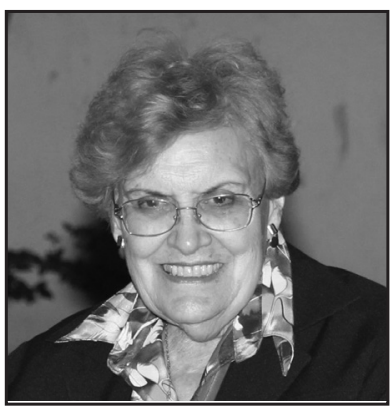
interés por la botánica desempeñándose como docente de la Facultad de Agronomía en calidad de Ayudante de primera en la cátedra de Botánica Agrícola hasta el año 1967, año en que ingresó como investigadora al Instituto de Botánica Darwinion y como miembro de la Carrera del Investigador Científico del CONICET.

En este Instituto desarrolló su carrera científica, realizando investigaciones en varios géneros de Cyperaceae, entre ellos Rhynchospora y en las otras familias ya mencionadas. Integró numerosos proyectos florísticos y participó en numerosas floras regionales como Flora de la Provincia de Entre Ríos, Estudios botánicos en la precordillera de San Juan, Catálogo de las plantas vasculares de la República Argentina, Flora del Cono Sur y Catálogo de las plantas vasculares de Bolivia. Sus antecedentes le permitieron ser beneficiada con becas internacionales, para realizar estadías en herbarios de Estados Unidos, entre ellos el New York Botanical Garden y además visitar herbarios de Europa, como el Conservatoire et Jardin botaniques de Genève, Suiza.

También fue galardonada con premios como el "Cristóbal M. Hicken" en 1971, otorgado por la Academia Nacional de Ciencias Exactas, Físicas y Naturales.

Su gran interés y dedicación hizo que entusiasmara a realizar estudios botánicos a numerosos investigadores y naturalistas en disciplinas como Diversidad vegetal, Taxonomía, Anatomía, entre otras, a quienes volcó sus conocimientos y experiencia, manifestándose como una docente nata. Publicó más de sesenta trabajos científicos en revistas botánicas nacionales e internacionales, especialmente en Darwiniana y en Floras regionales.

Durante muchos años tuvo relación tanto laboral como afectiva con investigadores del IBONE, con quienes colaboró desinteresadamente en temas y trabajos referentes al grupo vegetal que la ocupaba.

Todo lo expuesto hizo que a Rosa se la considerase una referente en los géneros de Cyperaceae de la flora del Cono Sur y que todas las generaciones que la conocieron la recuerden con mucho cariño por siempre. 
